\title{
MEREDUKSI CACAT BOTOL PLASTIK DENGAN PENDEKATAN SIX SIGMA DAN FUZZY
}

\author{
Fahmi Indra Nurrakhman 1), Dwi Nurul Izzhati'2), Rudi Tjahyono ${ }^{3)}$ \\ Teknik Industri, Fakultas Teknik, Universitas Dian Nuswantoro \\ Jl. Nakula I No 5-11 Semarang, Jawa Tengah 50131 \\ Email: fahmiindran@gmail.com¹), dwi.nurul.izzhati@dsn.dinus.ac.id²), \\ rudi.tjahyono@dsn.dinus.ac.id ${ }^{3)}$
}

\begin{abstract}
CV Jordan is plastics manufacturing company located in Semarang, Central Java. One of the products produced is PET plastic bottle. In an effort to control products quality, the company has a defects target with maximum value of $2 \%$ per month. However, in fact, the number of product defect increased to 4.69\% in October 2018 to March 2019. In this paper, Six Sigma method is used as an approach to overcome the problem of reducing products defects. The stages of Six Sigma method consist of Define, Measure, Analyze, Improve and Control. Even though, the limitation in this paper does not to examine control stage. At Define stage, types of defects identified in PET bottle are leakage, lumpy body, drop test, cut line, shake, convex head, dirty oil, tilted neck, dent ring, slip, pseudo burn, pseudo white, oblique stretch, and thin thickness. Also identified, the cause of dominant defect is the temperature changes in preform machine. The Measure stage, DPMO during the period October 2018 to March 2019 was 46,912 pcs with sigma value of 3.18. Analysis of factors causing defects in the three highest types off defects ie dent ring, pseudo white and rocking are explained at the Analyze stage. In the Improve stage, the temperature of the preform heating machine is stabilized using the fuzzy logic method at 58음 Celsius.
\end{abstract}

Keywords : PET, Six Sigma, Quality Control, DMAIC, Fuzzy

\begin{abstract}
Abstrak
CV Jordan Plastik adalah perusahan plastik yang berada di Semarang. Produk yang dihasilkan diantaranya adalah botol plastik PET. Perusahaan menargetkan maksimal produk cacat rata-rata $2 \%$ perbulan, namun realisasinya ada kenaikan produk cacat pada periode Oktober 2018 sampai Maret 2019 menjadi 4,69\%. Untuk mengendalikan permasalahan ini dan mereduksi produk cacat, peneliti menggunakan pendekatan Metode Six Sigma.Tahapan dari metode Six Sigma meliputi Define, Measure, Analyze, Improve dan Control. Pada penelitian ini tidak membahas pada tahapan control hanya sampai tahap Improve. Pada tahap Define diketahui jenis cacatnya botol PET yaitu bocor, body menggumpal, drop test, garis motong, goyang, kepala cembung, kotor oli, leher miring, ring penyok, selip, semu gosong, semu putih, stretch miring, dan tebal tipis dan penyebab cacat dominan adalah suhu mesin preform berubah-ubah.Tahap Measure, DPMO selama periode Oktober 2018 sampai Maret 2019 sebesar 46.912 pcs dengan nilai sigma 3,18. Tahap Analyze, analisis faktor yang menyebabkan cacat pada tiga jenis cacat tertinggi yaitu ring penyok, semu putih dan goyang. Pada tahap Improve dilakukan penstabilan suhu mesin pemanas preform dengan metode logika fuzzy pada suhu 58 Celcius.
\end{abstract}

Kata Kunci : PET, Six Sigma, Pengendalian Kualitas, DMAIC, Fuzzy 


\section{Pendahuluan}

Situasi perindustrian manufaktur di Indonesia mengalami kemajuan yang cukup pesat, sehingga semakin banyak terjadi kompetisi yang cukup ketat diantara perusahaan-perusahaan untuk menarik minat dan daya tarik konsumen agar tetap bisa bersaing. Tentunya perusahaan akan menjaga kualitas produknya dan memberikan pelayanan yang terbaik agar kepuasaan konsumen tetap stabil dan terjaga. Tetapi situasi ini memaksa suatu perusaahan untuk terus menerus memperbaiki dan mempertahankan kualitas hasil produksi perusahaan. Upaya yang biasanya dilakukan untuk tetap menjaga agar dapat bersaing dengan perusahaan yakni meminimalkan jumlah defect pada proses produksi agar tidak terjadi pengulangan kembali proses produksi yang juga akan menambah biaya produksi [1].

Defect atau produk cacat yaitu kualitas suatu produk yang akan menyebabkan kesalahan yang cukup fatal terhadap suatu proses produksi perusahaan [1]. Apabila jumlah produk yang cacat atau defect semakin banyak tentu akan menurunkan bahkan merusak nama baik perusahaan dimata konsumen karena suatu konsumen akan menilai baik buruknya perusahaan dari segi produk yang dihasilkan perusahaan sesuai atau tidak dengan permintaan yang diinginkan [2].

Jordan Plastik atau CV. Jordan merupakan perusahaan yang bergerak di industri manufaktur proses produksi botol plastik yang berskala menengah ke atas. Jordan Plastik beralamat di Jalan Industri VXII no. 42 LIK (Lingkungan Industri Kecil), Bugangan Baru Semarang. Jenis botol Plastik yang di hasilkan dari CV Jordan adalah jenis botol HDPE (High Density Polyethylene), dan PET (Preform). Contoh hasil produksi dari PET yaitu PET $330 \mathrm{ml}$ Rocket, PET $\mathrm{J}$ 500, PET $250 \mathrm{ml}$ dan lain-lain. Mesin yang digunakan untuk PET adalah SBM (Streching Blow Moulding) dan ABM (Automatic Blow Moulding). Untuk contoh hasil produk HDPE sendiri di bagi menjadi dua mesin yaitu

1. Mesin Inject (INJ)

Contoh produk yang dari mesin inject hasilkan yaitu tutup cat, tutup gallon, tutup botol mineral dan masih banyak lagi.

2. Mesin Extrussion Blow Moulding (EBM)

Contoh produk yang dari mesin EBM hasilkan yaitu M 50060 gr, M 25025 gr, M 100 Not dan lain masih banyak lagi.

Tetapi dari keempat mesin tersebut masih banyak terdapat cacat atau defect khususnya pada hasil produksi PET dibandingkan produksi HDPE yang cacat produknya dapat di daur ulang dengan mesin mixing. Dalam proses produksi PET perusahaan mempunyai batas minimum standar untuk produk cacat yakni $2 \%$ per bulan akan tetapi jumlah produk cacat masih melebihi dari batas minimum dari yang perusahaan tentukan. Berikut data produksi dan persentase produk cacat bulan Oktober 2018 - Maret 2019.

Tabel 1. Cacat atau defect produk pada produksi PET periode Oktober- Desember 2018

\begin{tabular}{|r|r|r|r|}
\hline \multicolumn{1}{|c|}{ Bulan } & $\begin{array}{c}\text { Total } \\
\text { Produksi } \\
\text { (pcs) }\end{array}$ & $\begin{array}{c}\text { Reject } \\
\text { (pcs) }\end{array}$ & $\begin{array}{c}\text { Persentase } \\
(\%)\end{array}$ \\
\hline Oct-18 & 1088349 & 43041 & 3.95 \\
\hline Nov-18 & 1015536 & 43383 & 4.27 \\
\hline Dec-18 & 745274 & 38124 & 5.12 \\
\hline Jan-19 & 1056408 & 47786 & 4.52 \\
\hline Feb-19 & 918827 & 46427 & 5.05 \\
\hline Mar-19 & 1044356 & 56555 & 5.42 \\
\hline
\end{tabular}

Cacat atau defect untuk produksi PET tidak dapat didaur ulang sehingga produk yang cacat di jual ke penjual dengan harga yang seadanya hal ini menyebabkan kerugian untuk perusahaan. Untuk memperoleh suatu kualitas yang diharapkan oleh CV Jordan maka memerlukan peningkatan dalam hal kualitas. 


\section{Metode Penelitian}

Tahapan dalam metode Six Sigma adalah sebagai berikut:

a. Define

Pada tahapan dilakukan tindakan untuk mengetahui proses proses yang dilakukan di Departemen PET yang bertujuan untuk pengendalian kualitas agar persentase cacat dan nilai sigma meningkat.

Tahapannya :

a. Identifikasi jenis cacat pada produksi PET

b. Identifikasi faktopr penyebab defect menggunakan work sampling

b. Measure

Waktu kunjungan : Jam Buka +(Bil Random) x Jarak Kunjungan

Pada tahapan ini yang dilakukan adalah menentukan karakteristik kualitas, perhitungan diagram P Chart, DPMO, nilai sigma dan CTQ untuk menentukan jenis cacat tertinggi.

a. Penentuan CTQ (Critical to Quality)

Adalah atribut penting yang berkaitan suatu kepuasaan dan tomer [2]. Dalam penelitian ini CTQ di ambil dari perhitungan jumlah defect 3 terbesar dalam jenis cacat dari bulan Oktober 2018 sampai Maret 2019, kemudian mendefinisikan stratification penyebab cacat yang terdapat di produksi PET secara detail per jenis defect yang terjadi.

b. Perhitungan nilai six sigma dan DPMO (Defect Per Million Oppertunities)

Nilai DPU dan DPMO berfungsi untuk menghitung nilai six sigma dari keseluruhan hasil produksi di Produksi PET.

DPU (Defect Per Unit)

DPU $\quad=\frac{\text { Jumlah kerusakan }}{\text { Jumlah hasil produksi }}$

DPMO (Defect Per Million Oppertunities)

$\mathrm{DPMO}=\frac{\text { Jumlah cacat } / \text { defect }}{\text { Jumlah hasil produksi }}$

[2]

c. Analyze

Tahapan ini akan dilakukan analisa penyebab terjadinya masalah pada produksi botol jenis PET.

a. Menganalisis penerapan CTQ yang telah di hitung pada tahap measure.

b. Menganalisis diagram sebab akibat

d. Improve

Setelah mengetahui faktor utama penyebab kecacatan atau defect maka dilakukan rencana perbaikan. Perbaikan mengenai faktor penyebab defect yang dominan menggunakan logika fuzzy metode Tsukamoto. Tahapan dala fuzzy tsukamoto adalah

a. Fuzzufucation

Tahapan awal dimana untuk memetakan nilai fungsi keanggotaan yang akan di masukan ke dalam sistem fuzzy [4]. Data ini di ambil dari penelitian langsung di lantai produksi PET.

b. Rule Evaluation

Tahap rule evaluation akan dilakukan pengecekan, evaluasi, dan pengambilan keputusan dari himpunan fuzzy dengan penentuan aturan basis sesuai dengan kondisi yang ada di Produksi PET [5].

c. Aturan Infernce

Proses menggunakan fungsi MAX karena menggunakan penghubung OR untuk mendapatkan nilai $\alpha$-predikat dari tiap-tiap rule $(\alpha-1, \alpha-2, \alpha-3, \ldots)$. Setelah itu menghitung nilai keluaran hasil inference dari masing-masing rule $(z-1, z-2 . z-3, \ldots)[4]$.

d. Defuzzification

Applied Industrial Engineering Journal Vol. 03, No. 02, Desember 2019: 01 - 11 
Tahap ini memetakan nilai kedalam nilai fuzzy atau nilai crisp. Terdapat beberapa metode yang ada di defuzzication yaitu Centeroid, first of max, last of max, dan sebagainya [4]. Pada penelitian ini digunakan logika fuzzy metode Tsukamoto karena nilai yang paling mendekati dengan rumus $Z=\frac{\sum a-1 \cdot z-1}{a-1}$ [5].

\section{Hasil dan Analisis}

\subsection{Pengumpulan Data}

Pada tahapan pengumpulan data menggunakan data ptroduksi pada periode Oktober 2018 sampai Maret 2019 untuk mengetahui tingkat persentase tingkat cacat dan nilai sigma pada Departemen PET. Berikiut ini persentase cacat peride Oktober 2018 aampai 2019.

Tabel 2. Rekapituasi hasil proses produksi

\begin{tabular}{|c|c|c|c|}
\hline Bulan & $\begin{array}{c}\text { Total } \\
\text { Produksi } \\
\text { (pcs) }\end{array}$ & $\begin{array}{c}\text { Reject } \\
\text { (pcs) }\end{array}$ & $\begin{array}{c}\text { Presentase } \\
(\%)\end{array}$ \\
\hline Oct-18 & 1088349 & 43041 & 3,95 \\
\hline Nov-18 & 1015536 & 43383 & 4,27 \\
\hline Dec-18 & 745274 & 38124 & 5,12 \\
\hline Jan-19 & 1056408 & 47786 & 4,52 \\
\hline Feb-19 & 918827 & 46427 & 5,05 \\
\hline Mar-19 & 1044356 & 56555 & 5,42 \\
\hline
\end{tabular}

\subsection{Pengolahan Data}

Dalam proses pengolahan data pengendalian kualitas ada beberapa tahap yang meliputi define, measure, analyze, improve dan control [3].

1. Define

a. Identifikasi jenis cacat yang menjadi faktor utama cacat pada produk

Berdasarkan permasalahan pada perusahaan terdapat bocor, body menggumpal, drop test, garis motong, goyang, kepala cembung, kotor oli, leher miring, ring penyok, selip/nyisil, semu gosong, semu putih, stretch miring dan tebal tipis.

Tabel 3. Jenis cacat yang menjadi faktor utama cacat produk

\begin{tabular}{|l|l|}
\hline \multicolumn{1}{|c|}{ Jenis Cacat } & \multicolumn{1}{c|}{ Definisi } \\
\hline Bocor & Cacat yang berbentuk lubang yang jelas yang dapat di lihat oleh mata \\
\hline Drop test & Cacat yang terlihat apabila dites dengan di isi air \\
\hline Garis motong & $\begin{array}{l}\text { Cacat yang terdapat bagian leher botol terdapat warna yang tidak } \\
\text { sama }\end{array}$ \\
\hline Semu putih & $\begin{array}{l}\text { Cacat yang berakibat warna dari botol tidak bening atau berwarna } \\
\text { sedikit putih }\end{array}$ \\
\hline Goyang & $\begin{array}{l}\text { Cacat yang di terjadi karena preform dicetak tidak merata sehingga } \\
\text { permukaan pada bagian badan botol tidak sama }\end{array}$ \\
\hline Kepala cembung & Cacat yang mengakibatkan kepala botol tidak rata \\
\hline Kotor oli & Cacat pada bagian dalam botol berbentuk bintik hitam \\
\hline Leher miring & $\begin{array}{l}\text { Cacat yang terdapat pada leher botol satu dengan yang lainnya tidak } \\
\text { lurus }\end{array}$ \\
\hline Ring penyok & Ring penyok terdapat pada bagian kepala botol \\
\hline Selip/nyicil & Tidak rata pada bagian badan botol titik temu botol \\
\hline Semu gosong & Terdapat warna putih yang cukup besar pada bagian pantat botol \\
\hline Strech miring & $\begin{array}{l}\text { Cacat yang garis titik tengah pada bagian pantat botol tidak pas pada } \\
\text { tengah }\end{array}$ \\
\hline Body menggumpal & Cacat pada bagian tubuh botol terdapat gumpalan seperti gelembung \\
\hline
\end{tabular}

Applied Industrial Engineering Journal Vol. 03, No. 02, Desember 2019: $01-11$ 
b. Identifikasi jenis cacat yang menjadi faktor utama cacat pada produk Pada penelitian ini menggunakan work sampling dengan waktu kunjungan 10 menit. Berikut hasil work sampling:

Tabel 4. Frekuensi faktor penyebab defect

\begin{tabular}{|l|r|r|}
\hline Penyebab Defect & Jumlah & \multicolumn{1}{|c|}{$\begin{array}{c}\text { Persentase } \\
\text { (100\%) }\end{array}$} \\
\hline $\begin{array}{l}\text { Suhu Pemanas } \\
\text { Berubah }\end{array}$ & 88 & 42,11 \\
\hline Human error & 47 & 22,49 \\
\hline Sill kotor & 29 & 13,88 \\
\hline $\begin{array}{l}\text { Tekanan Angin tdk } \\
\text { sesuai }\end{array}$ & 23 & 11,00 \\
\hline Molding Bergeser & 14 & 6,70 \\
\hline Kualitas Preform & 8 & 3,83 \\
\hline
\end{tabular}

\section{Measure}

a. Penetapan CTQ

Penepatan CTQ untuk mentukan jenis cacat terbesar. Berikut Tabel rekap perhitungan CTQ.

Tabel 5. Rekapitusi 3 jenis cacat produk tertinggi PET

\begin{tabular}{|l|r|}
\hline Jenis Cacat & Jumlah cacat \\
\hline Goyang & 37473 \\
\hline Semu putih & 72733 \\
\hline Ring penyok & 29486 \\
\hline
\end{tabular}

b. Perhitungan Nilai DPMO (Defect per Million Opportunities) dan nilai six sigma Nilai DPU dan DPMO dihitung untuk mengukur nilai six sigma dari hasil produksi di CV Jordan Plastik, caranya sebagai berikut :

Tabel 6. Hasil rekapitulasi perhitungan DPU, DPMO dan Six Sigma bulan Oktober 2018- Maret 2019

\begin{tabular}{|l|r|r|}
\hline \multicolumn{1}{|c|}{ Bulan } & DPMO & \multicolumn{1}{c|}{ Nilai Sigma } \\
\hline Oct-18 & 39547 & 3,26 \\
\hline Nov-18 & 42719 & 3,22 \\
\hline Dec-18 & 51155 & 3,13 \\
\hline Jan-19 & 44824 & 3,20 \\
\hline Feb-19 & 50528 & 3,14 \\
\hline Mar-19 & 54153 & 3,11 \\
\hline Rata-rata & 46912 & 3,18 \\
\hline
\end{tabular}




\section{Analyze}

Analyze merupakan lanjutan dari hasil pengolahan data ditahap measure. Pada tahapan ini dilakukan analisa CTQ (Critical To Quality) dengan Diagram Sebab Akibat Berdasarkan data yang ada di tahap measure telah di dapatkan 3 jenis cacat atau defect produk yaitu Semu putih, goyang dan ring penyok.

Tiga cacat tersebut diidentifikasikan sebagai berikut :

1. Semu putih

Cacat jenis semu putih adalah jenis cacat produk yang berbentuk seperti goresan berwarna putih yang seharusnya berwarna bening, hal ini biasanya disebabkan karena suhu pemanas preform tidak stabil sehingga menyebabkan tidak meratanya panas preform.

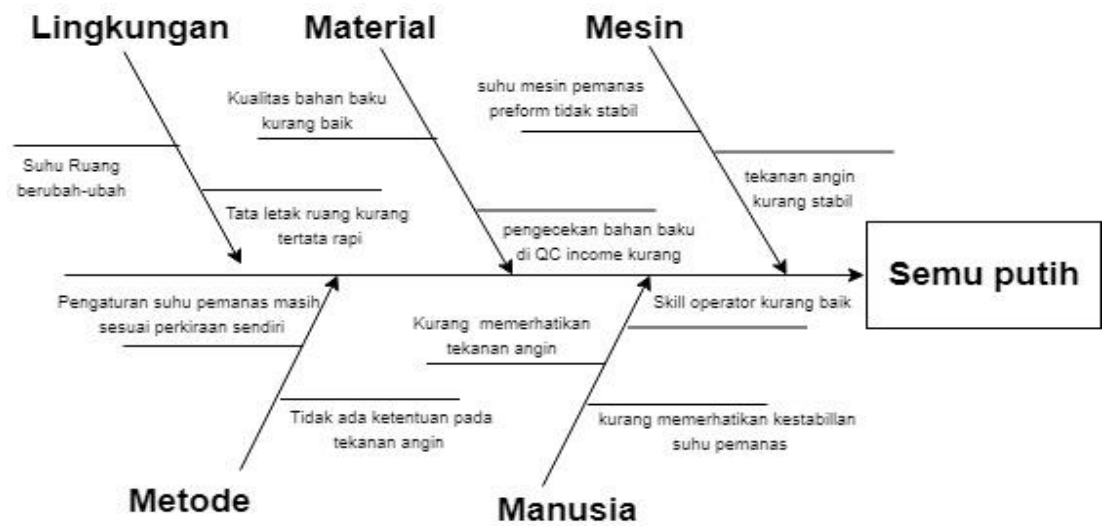

Gambar 1. Sebab akibat semu putih

\section{Goyang}

Goyang merupakan jenis cacat yang bentuk botolnya tidak lurus atau sisi satu dan yang lain tidak sama atau simetris biasanya disebabkan karena molding bergeser, suhu pemanas preform tidak stabil dan tekanan yang dikeluarkan kompresor tidak sesuai.

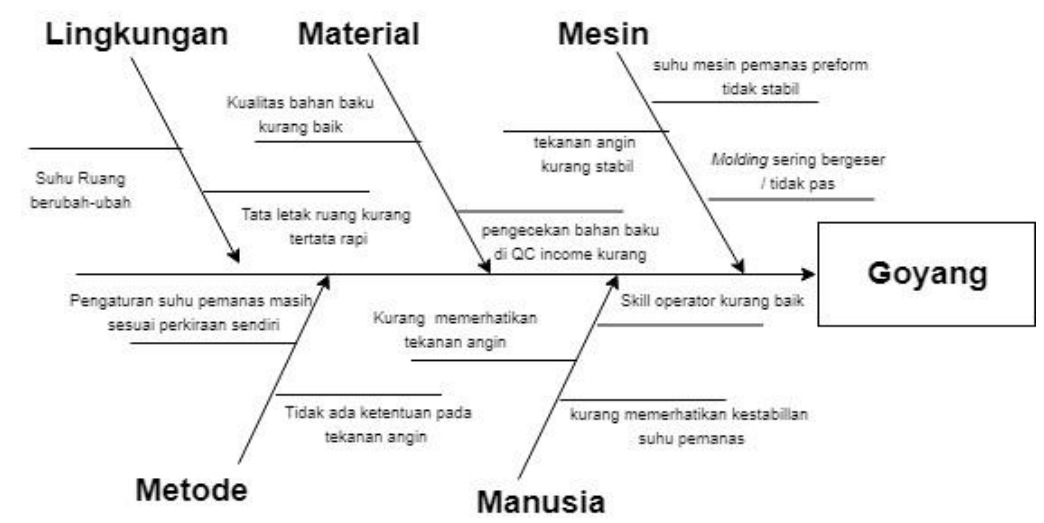

Gambar 2. Sebab akibat goyang

3. Ring penyok

Cacat jenis produk ring penyok adalah cacat pada bagian tutup botol yang dikarenakan 
karena perlakuan botol yang tidak baik atau terjatuh dan suhu pemanas preform kurang stabil.

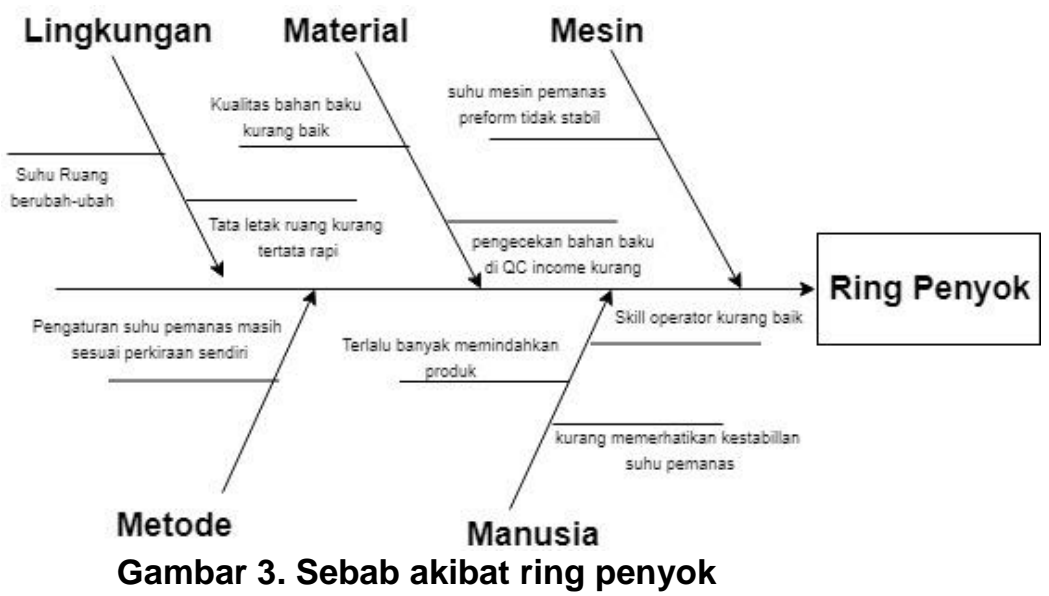

\section{Improve}

Pada tahap improve ini akan dilakukan perbaikan yang berkaitan dengan suhu pemanas preform dimana dari metode work sampling merupakan faktor yang paling dominan

Tabel 7. Variabel input logika fuzzy

\begin{tabular}{|c|c|c|c|}
\hline \multicolumn{2}{|c|}{ Variabel } & Himpunan Fuzzy & Range \\
\hline \multirow[t]{5}{*}{ Input } & \multirow{3}{*}{$\begin{array}{l}\text { Suhu } \\
\text { mesin }\end{array}$} & Dingin & {$[0-58]$} \\
\hline & & Sedang & {$[50-69]$} \\
\hline & & Panas & {$[58-100]$} \\
\hline & \multirow{2}{*}{ Error } & Minus & {$\left[\begin{array}{ll}-8 & 0\end{array}\right]$} \\
\hline & & Plus & {$\left[\begin{array}{ll}0 & 11\end{array}\right]$} \\
\hline \multirow[t]{12}{*}{ Output } & \multirow{3}{*}{ SCR 1} & Turun & {$\left[\begin{array}{ll}148 & 155\end{array}\right]$} \\
\hline & & Normal & [148 162] \\
\hline & & Naik & [155 162] \\
\hline & \multirow{3}{*}{ SCR 2} & Turun & [117 135] \\
\hline & & Normal & [117 - 153] \\
\hline & & Naik & [135-153] \\
\hline & \multirow{3}{*}{ SCR 3} & Turun & {$[50-70]$} \\
\hline & & Normal & [50 - 90] \\
\hline & & Naik & [70 - 90] \\
\hline & \multirow{3}{*}{ SCR 4} & Turun & {$[88-100]$} \\
\hline & & Normal & {$[88-112]$} \\
\hline & & Naik & [100 - 112] \\
\hline
\end{tabular}


Inference engine untuk menentukan nilai ouput yang berasal dari suhu mesin. Ada 3 rules yang diperoleh sebagai berikut

Tabel 8. Inference Engine Rules

\begin{tabular}{|c|c|c|c|c|c|c|c|}
\hline \multirow[b]{2}{*}{ RULES } & \multicolumn{3}{|c|}{ IF } & \multicolumn{4}{|c|}{ THEN } \\
\hline & $\begin{array}{l}\text { SUHU } \\
\text { MESIN }\end{array}$ & Inference & Error & SCR 1 & SCR 2 & SCR 3 & SCR 4 \\
\hline $\mathrm{R} 1$ & Dingin & \multirow{3}{*}{ OR } & Minus & Naik & Naik & Naik & Naik \\
\hline $\mathrm{R} 2$ & Sedang & & & Normal & Normal & Normal & Normal \\
\hline R3 & Panas & & Plus & Turun & Turun & Turun & Turun \\
\hline
\end{tabular}

Perancangan sistem menggunakan arduino bertujuan untuk menstabilkan suhu mesin yang sering berubah sehingga menyebabkan defect. Pada tahap simulasi akan diimplementasikan menggunakan alat seperti arduino, ac light dimmer, solder, laptop dan sensor suhu Im35 (thermocouple).

Pada penelitian ini suhu distabilkan diangka 58 Celcius karena suhu mesin pemanas preform yang sering berubah-ubah menunjukkan bahwa mesin pemanas preform lebih stabil diangka 58 Celcius. Berikut tabel perhitungan jumlah produk cacat apabila mesin pemanas preform di stabilkan.

Tabel 9. Rekapitulasi perbandingan kondisi awal dan kondisi perbaikan nilai sigma

\begin{tabular}{|c|c|c|}
\hline Perbandingan & $\begin{array}{c}\text { Kondisi } \\
\text { Awal }\end{array}$ & $\begin{array}{c}\text { Kondisi } \\
\text { Akhir }\end{array}$ \\
\hline Jumlah Produksi & 5868750 & 5868750 \\
\hline Jumlah defect & 275316 & 159380 \\
\hline Persentase defect & 4,69122 & 2,71575 \\
\hline Nilai DPMO & 46912 & 27157 \\
\hline Nilai Sigma & 3,18 & 3,50 \\
\hline
\end{tabular}

Dengan menstabilkan suhu mesin menjadi tetap di angka 58 Celcius akan dapat mengurangi jumlah defect atau cacat karena dari hasil observasi work sampling suhu pemanas preform berpengaruh 42,11\%. Sehingga jumlah defect atau cacat dari bulan oktober 2018 sampai Maret 2019 dapat diperkirakan berkurang $42,11 \%$ dari 275.316 pcs menjadi 159.381 pcs atau berkurang 115.936 pcs dari 5.868 .750 pcs total produksi. Artinya presentase jumlah produk cacat atau defect dari $4.69 \%$ menjadi $2,72 \%$ dan nilai sigma dapat meningkat dari 3,18 menjadi 3,50.

\section{KESIMPULAN}

1. Berdasarkan hasil pengolahan data dan analisa menunjukkan bahwa faktor penyebab cacat atau defect produk adalah manusia (man), bahan baku (material), mesin (machine), lingkungan (environment) dan Metode (method). Dari faktor manusia yang mempengaruhi adalah kurangnya skill operator yang kurang dalam penyettingan mesin pemanas preform dan kompressor. Dari faktor bahan baku yakni kualitas bahan baku kurang baik. Dari 
faktor mesin yaitu suhu mesin preform dan tekanan angin yang tidak stabil. Dari faktor lingkungan tata letak yang kurang baik dan dari faktor metode yaitu pengaturan suhu yang tidak ada di perusahaan serta masih sesuai perkiraan dari operator. Berdasarkan perhitungan work sampling dari 5 faktor tersebut yang sangat berpengaruh dalam penyebab defect atau cacat adalah dari faktor mesin yaitu mesin preform yang sering berubah.

2.Cara pengendalian kualitas produk botol plastik jenis PET dengan six sigma yang pertama yaitu Define. .Define untuk mengidentifikasi jenis cacat yang berada di PET CV Jordan Plastik yaitu bocor, body menggumpal, drop test, garis motong, goyang, kepala cembung, kotor oli, leher miring, ring penyok, selip, semu gosong, semu putih, stretch miring, tebal tipis dan pada tahapan define juga mengidentifikasi faktor penyebab defect atau cacat menggunakan work sampling dengan hasil mesin pemanas preform yang berubah-ubah. Di Tahapan Measure diperoleh hasil perhitungan Critical to Quality diperoleh tiga cacat tertinggi yaitu Semu putih, goyang dan ring penyok. Dan nilai sigma rata-rata dari bulan Oktober 2018 sampai Maret 2019 yaitu 3,18. Artinya dari sejuta kesempatan ada 46.912 pcs produk cacat. Di Analyze dilakukan analisa dengan diagram sebab akibat tiga cacat atau defect tertinggi dari perhitungan CTQ. Pada tahap Improve disimulasikan dengan aplikasi Arduino IDE untuk menstabilkan suhu mesin di angka 58 Celcius dengan metode logika fuzzy.

\section{Referensi}

[1] Gasperz, V. (2001). Total Quality Management. Jakarta : PT, Gramedia Utama.

[2] Gasperz, V. (2003). Total Quality Management. Jakarta : PT, Gramedia Utama.

[3] Pete \& Holpp. 2002. What is Six Sigma. Yogyakarta : Andi.

[4] Kusumadewi, S. (2004). Aplikasi Logika Fuzzy untuk Pendukung Keputusan. Yogyakarta : Graha Ilmu.

[5] Kusumadewi, "Sri \& Purnomo, H. 2010. Aplikasi Logika Fuzzy Untuk Pendukung Keputusan. Yogyakarta : Graha IImu. 